\title{
Application of Digital Terrain Model (DTM) and Computer- Aided Techniques for Relief Representation
}

\author{
$1^{\text {st }}$ Dr. Huda Abdulmalik Thanoon ${ }^{1}, 2^{\text {nd }}$ Qusay Kader Ismail. Khalil ${ }^{2}$ \\ \{hudathanoon@yahoo.com¹ ${ }^{1}$ qusayprince@gmail.com²
}

Northern Technical University, Mosul-Iraq ${ }^{1}$, Northern Technical University, Mosul-Iraq ${ }^{2}$

\begin{abstract}
The aim of this research is to explore the use of digital terrain model (DTM) for relief representation using different software's programming. DTM was acquired from terrestrial surveying using total station devise Topcon GTS-235N. Three computer software's were utilized for relief representation namely (GIS, Surfer and AutoCAD Civil 3D Land). 2D and 3D relief representations were performed for the study area by using (GIS) techniques. Furthermore, a study of the application of the Surfer and AutoCAD Civil 3D Land software's for relief representation was investigated. The study area was located in Mosul north Iraq. The results demonstrated that the automated derivation of the spatial analysis and relief representation of the topography surface from digital data is faster, providing more reproducible applications for terrain representation. GIS techniques have gained a prominent role in relief representation than Surfer and AutoCAD Civil 3D Land software's.
\end{abstract}

Key words: DTM, GIS, Surfer, AutoCAD Civil 3D Land, Relief representation

\section{Introduction}

Relief representation is a necessary aid in the design of all engineering projects that require consideration of landform and elevation. Recent advance in digital land survey, digital Photogrammetry, geographical information system, software's and computer techniques provide a wide range of possibilities for digital data acquisition for, mapping and terrain representation These techniques allow efficient, economical and quick data collection, processing and analysis of the terrain surface and relief. Geographical information system (GIS) definition is a digital system for acquisition, management, analysis and. visualization of spatial data for the purposes of planning, administering and monitoring the natural and socio-economic environment [1]. The GIS is a relatively new technology that joins the computer science advantages with the modern systems of the capture of data, so that it allows the integration and the treatment of all types of information [2]. Photogrammetry and the GIS provide a group of advantages and benefits in the architectural tasks impossible to obtain with such efficiency, velocity and economy by means of other procedures [2]. Thanoon and Ahmed study the possibilities of integrating remote sensing, geographic information system and digital elevation model linked and imported with several software's [3]. They concluded that this integration was 
provide wide range for creating thematic databases of the watershed for dams site selection.

\section{Scope of the study}

The purpose of this research to know the relation between digital Land surveying, Digital photogrammetry, GIS, Surfer and AutoCAD Civil 3D Land software's according to their use and who they can work together. Furthermore, to know which one can depend to represent surface relief in suitable matching to the topographic surface.

\section{Methodology}

\subsection{Collecting data using Land surveying}

The area under investigation was characterized by hilly to plain terrain with undulating to flat relief. Digital Terrain Model (DTM) data collection was performed using devise total station Topcon GTS$235 \mathrm{~N}$. A total of 111 points were collected to represent the study area. The sampling pattern was performed by using points distributed over the whole area with special emphasis on the region that indicates the significant changes in the terrain slope. The distribution of the points and their elevations as shown in Figure 1. The elevations were ranging from 229 to 245 above sea level.

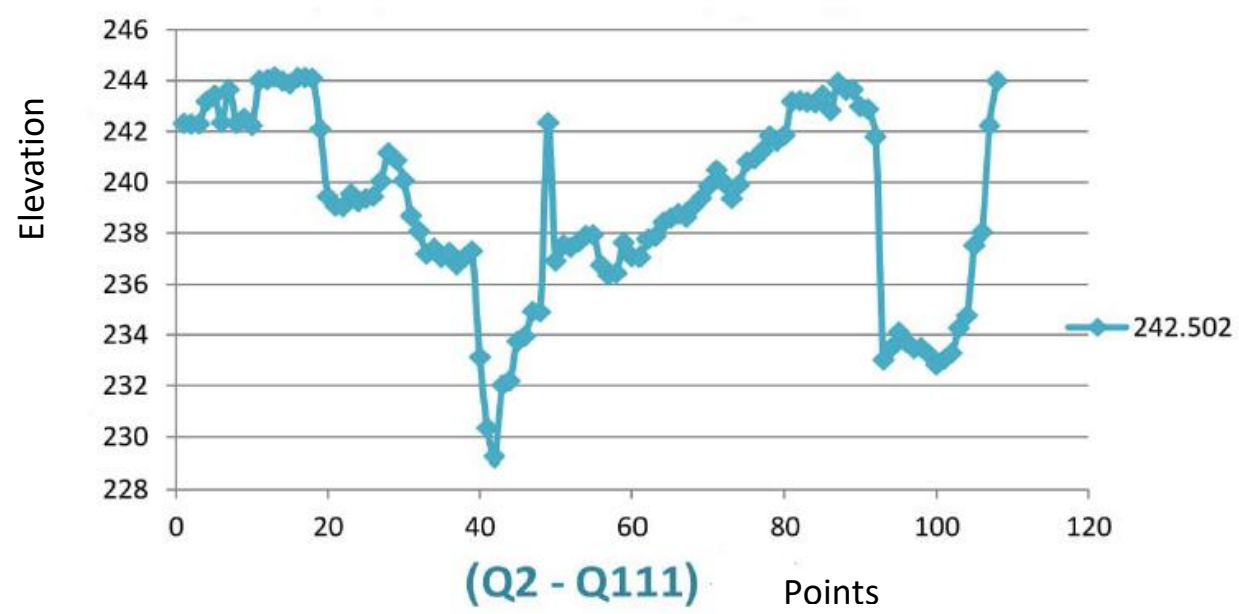

Fig. 1. Elevations distribution of the Digital Terrain Model (DTM).

The collected data was transformed to the computer using Topcon Link v8.0 program as shown in Figure 2. Checking the positions and the accuracy of collecting data of the DTM GIS program 
ArcMap was used to add X, Y coordinates data over a digital aerial photograph with ground control point of the study area as shown in Figure 3.



Fig. 2. Topcon Link v8.0 program link.

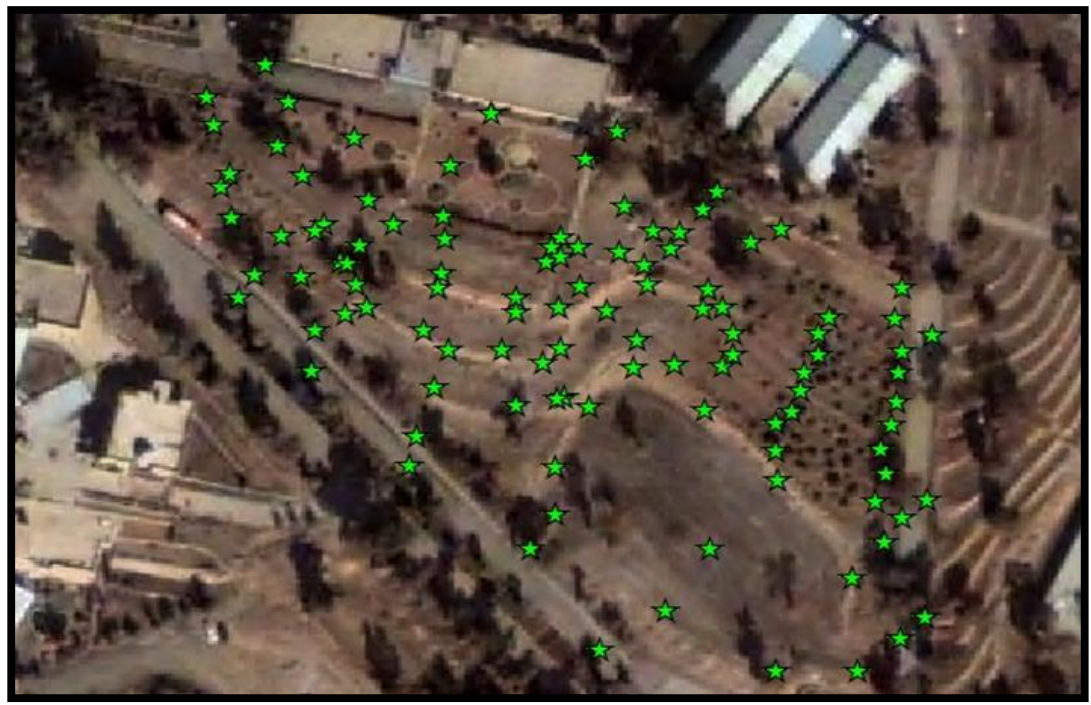

Fig. 3. Checking the position of the collected DTM

\subsection{Computer Software's for terrain relief representation}

In order to represent terrain relief from DTM different software's were used in this study namely Surfer 13, GIS v1.3 (ArcMap, ArcScene) and AutoCAD Civil 3D Land [4,5 and 6]. 


\section{Results and Discussion}

Kriging interpolation method was used to generate grid data from the DTM in Surfer software. Relief representation using Surfer software was illustrated in Figures 4 -7. respectively. Two contour maps with $5 \mathrm{~m}$ and $1 \mathrm{~m}$ interval were computed from the DTM. Figures 4 and 5 showed the contour maps with $5 \mathrm{~m}$ and $1 \mathrm{~m}$ respectively. Open and parallel contour lines were appeared in the plots with the highest values in the hilly region and lowered values towered the flat region.

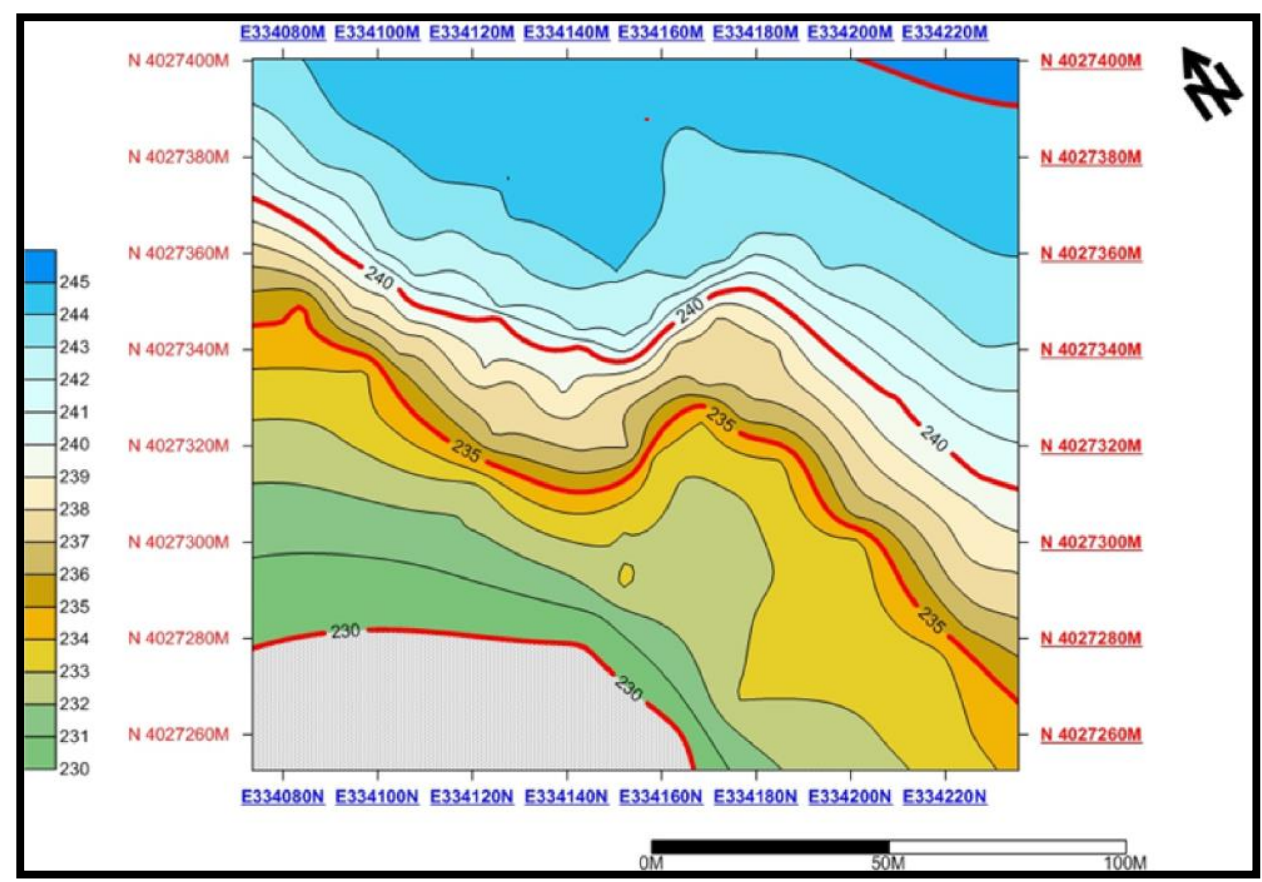

Fig 4. Contour map with $5 \mathrm{~m}$ interval. 


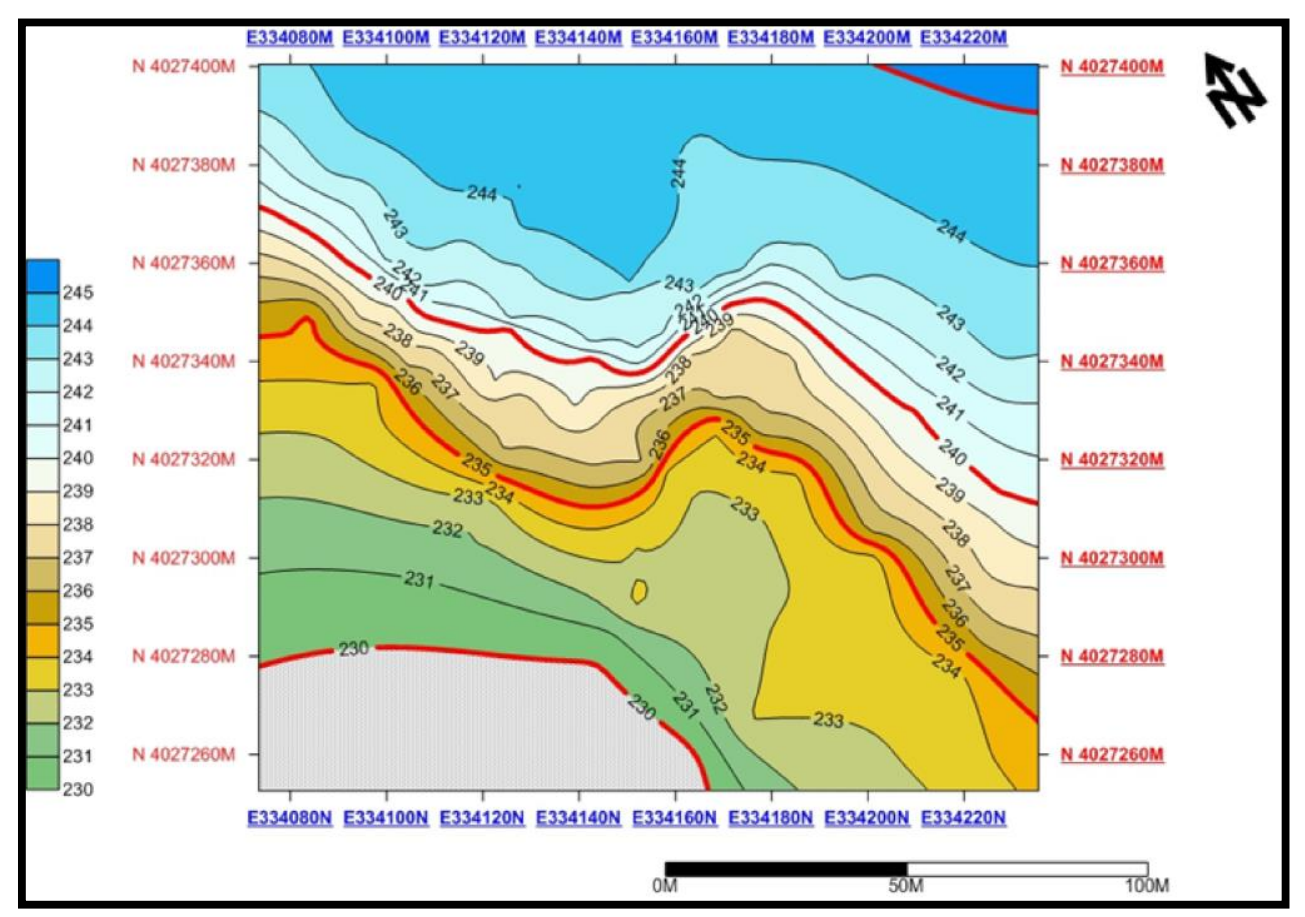

Fig. 5. Contour map with $1 \mathrm{~m}$ interval.

3D perspective view diagram was derived from DTM data. The combination of the 3D, vector and contour maps was illustrated in Figure 6. The arrows of the vector map were following the same tendency of the slope changing of the terrain surface from the hilly region towered the flat region. The shaded relief representation using was showed in Figure 7 . The dark gray tone was referred to as the portions of the surface area away from light source and then reflected low light.

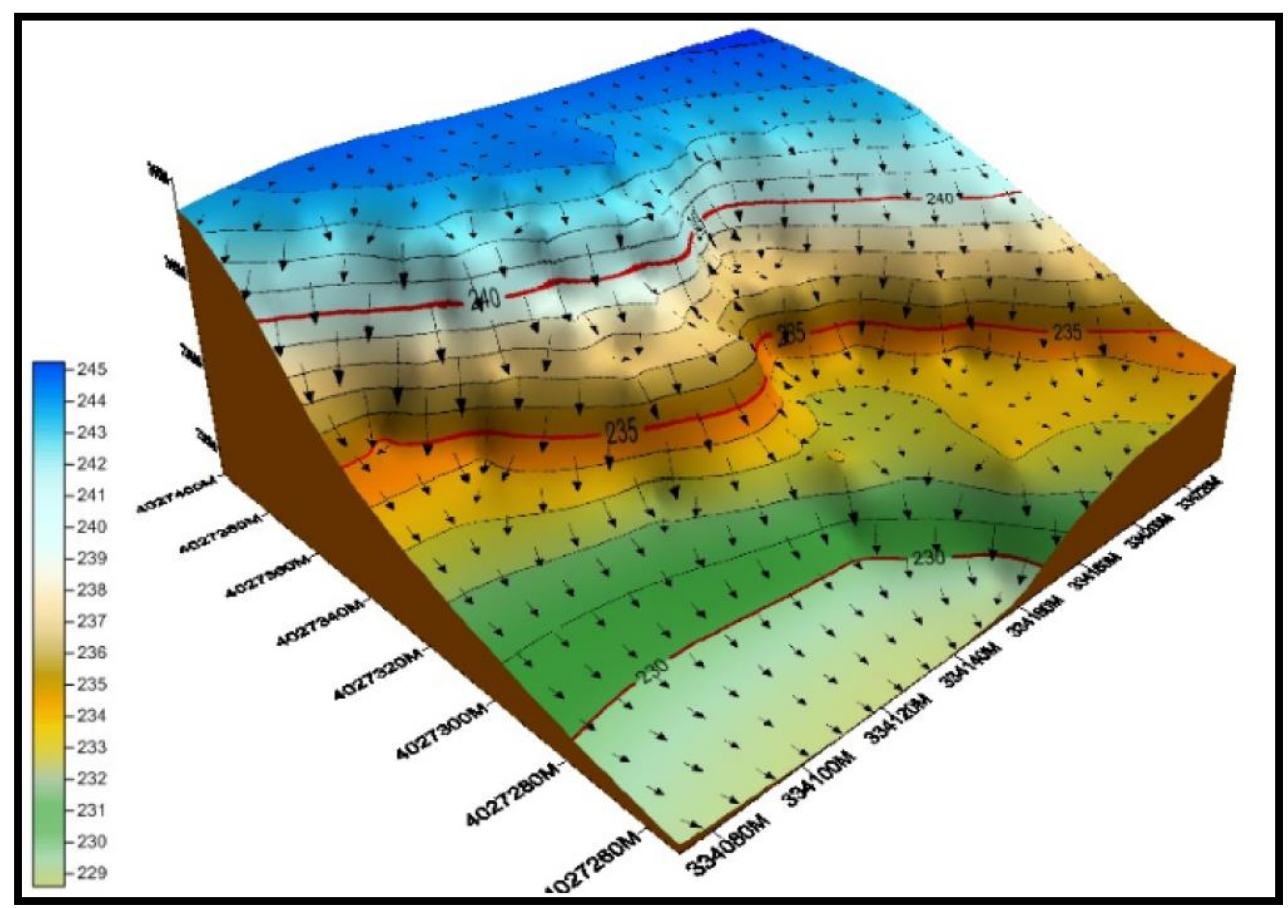




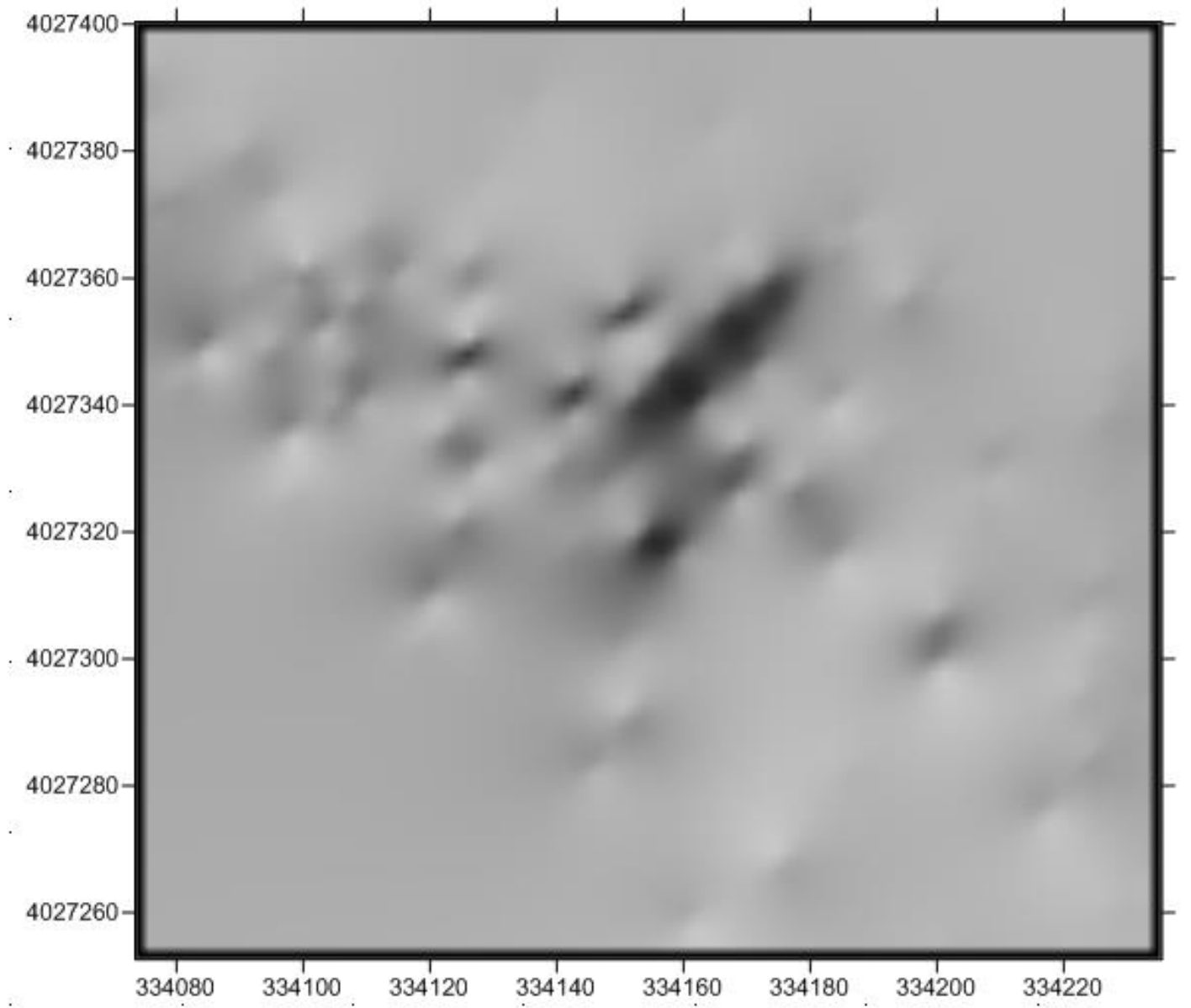

Fig. 7. The shaded relief representation.

Relief representation using GIS software was shown in Figures 8-14 respectively. Figure 8 and 9 illustrated a spatial analyst tools with the kriging and spline interpolation methods respectively. As Shown different interpolation methods lead to different generations of points and representation shape of the contour lines. 


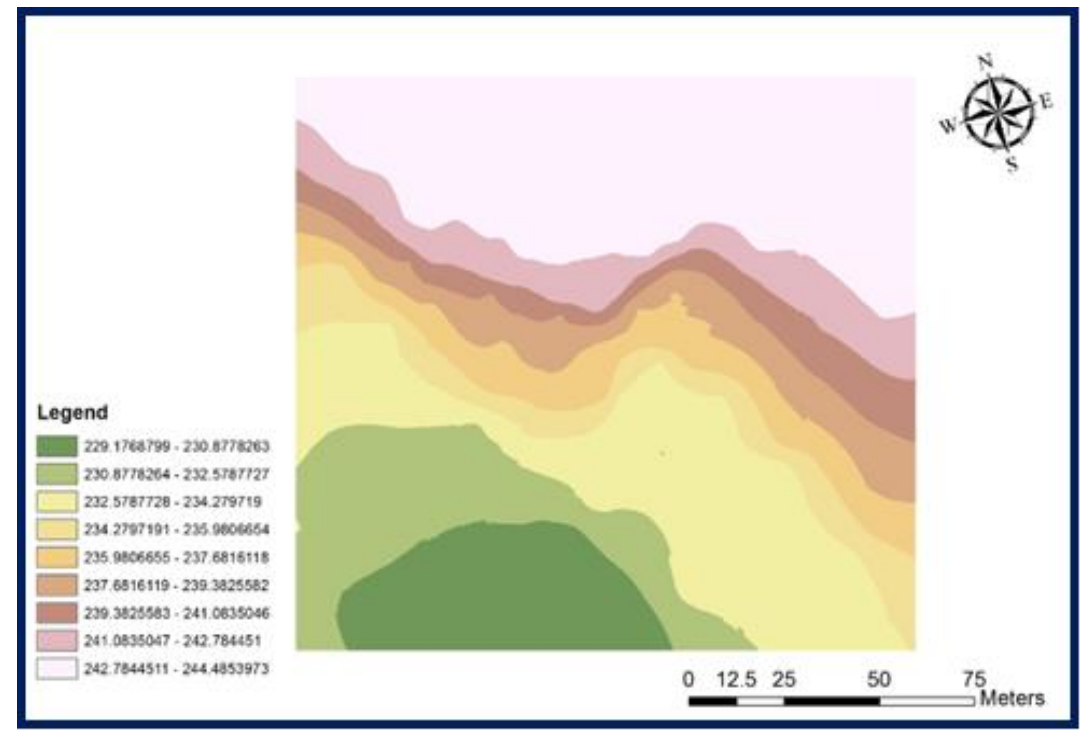

Fig 8. Spatial analyst tools with interpolation method kriging.



Fig 9. Spatial analyst tools with interpolation method spline.

A contour map with a $1 \mathrm{~m}$ interval was derived from DTM using spline interpolation method. Figures 10 and 11 showed the contour map and the contour map overlay the digital aerial photograph respectively. Closed contour lines have appeared in this diagram which indicates hilly terrain surface. Furthermore, the contour lines shape following the tendency of the interpolation method. 


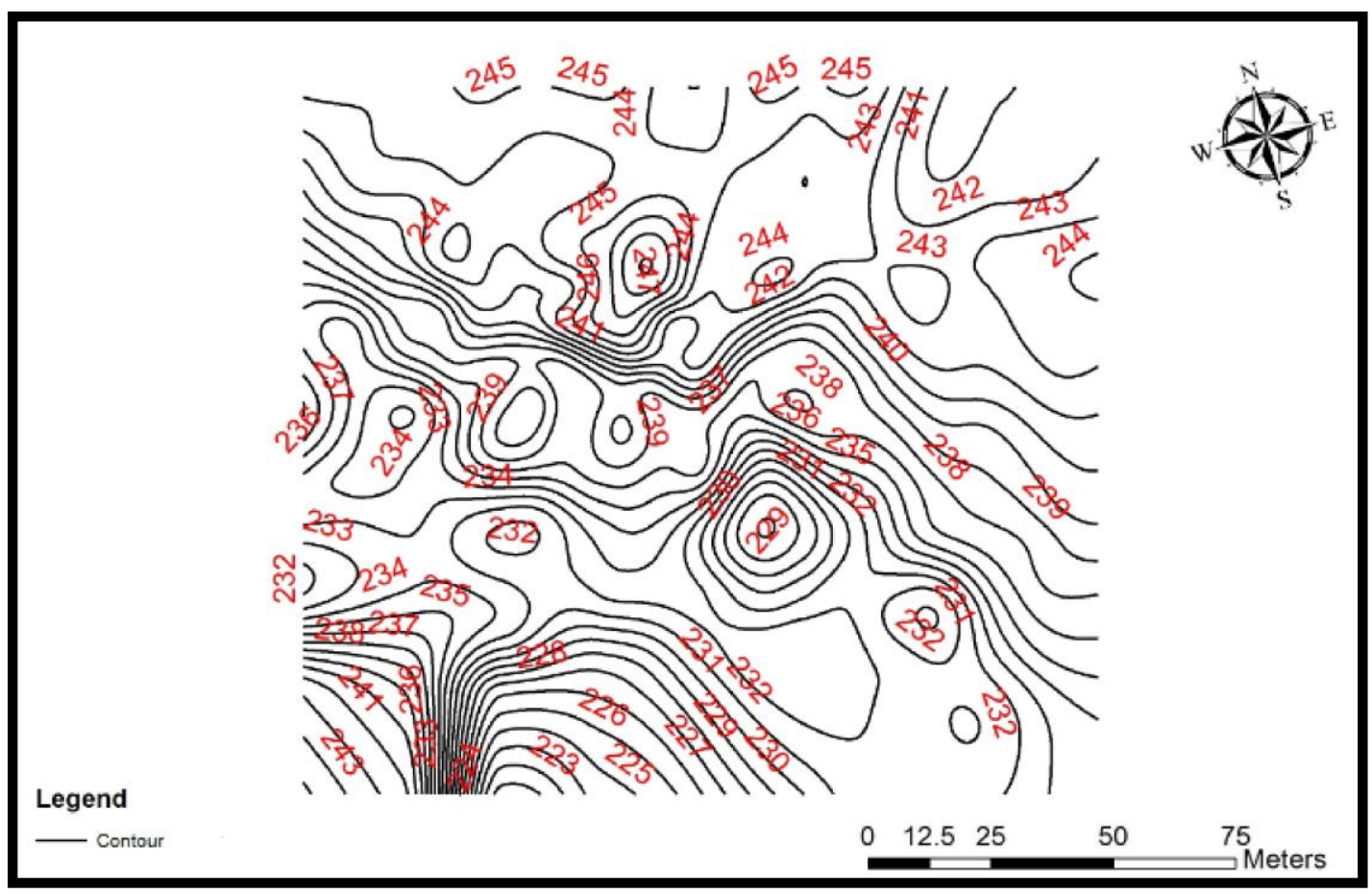

Fig. 10. Contour map with $1 \mathrm{~m}$ interval.

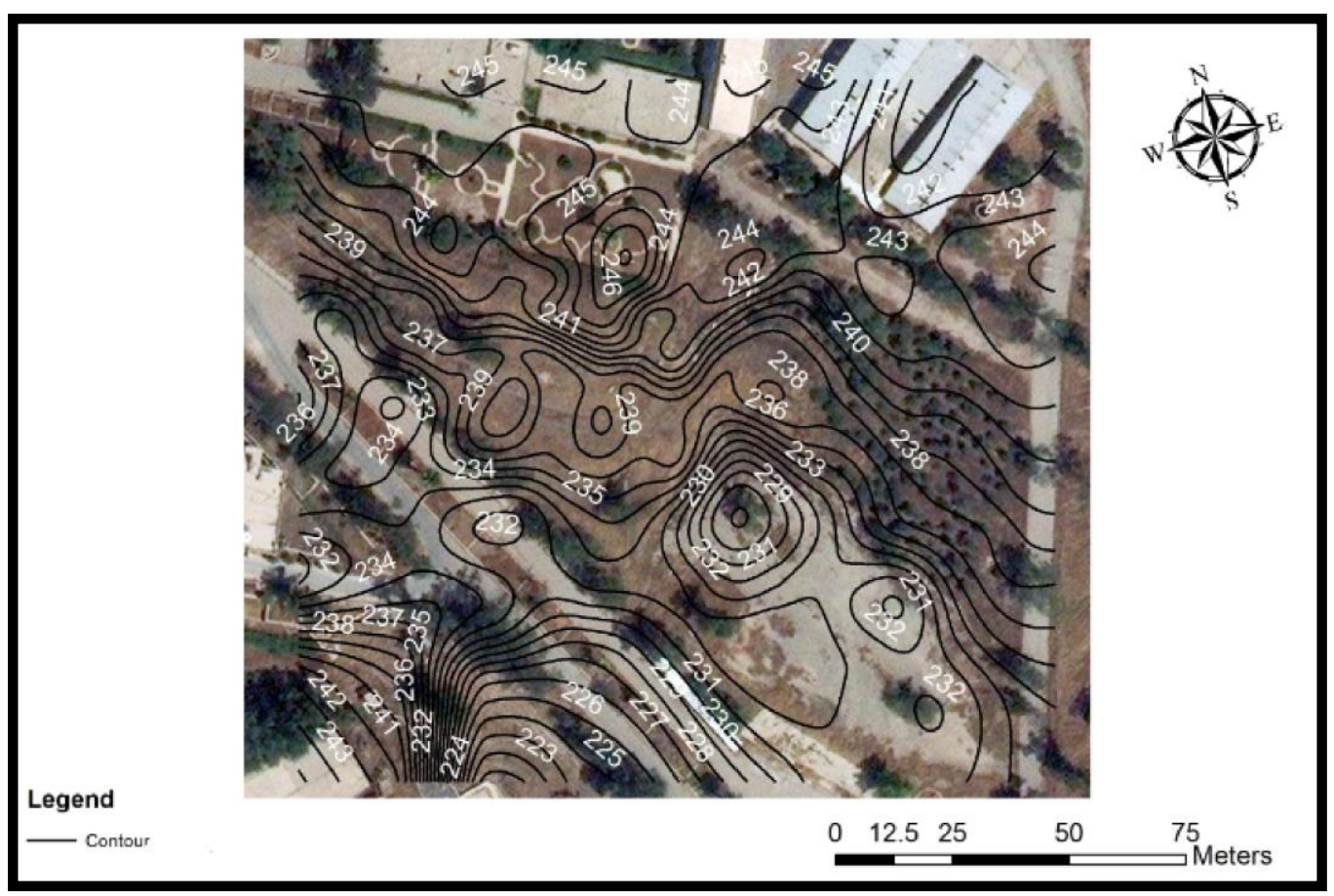

Fig.11. Contour map with $1 \mathrm{~m}$ interval overlay the digital aerial photograph. 
A hillshade map was shown in Figure 12. The dark gray tone was represented the regions of low reflected of the light source and appeared in the hilly terrain clearly. Using 3D analyst tools the combination of the tin representation overlay the digital aerial photograph was shown in Figure 13. By using GIS ArcScene the combination of the 3D tin and digital aerial photograph with transparency was shown in Figure 14. Clear matching was observed between the tin transparency plot and terrain topographic surface in the aerial photograph.



Fig. 12. Hillshade representation. 


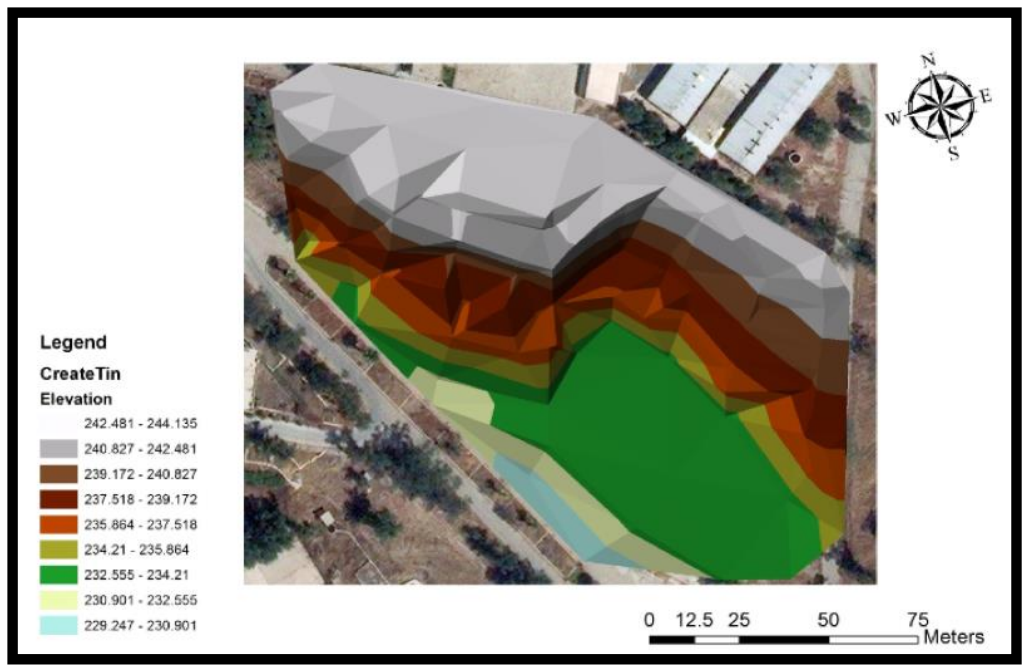

Fig. 13. Combination of the tin representation overlay the digital aerial photograph.

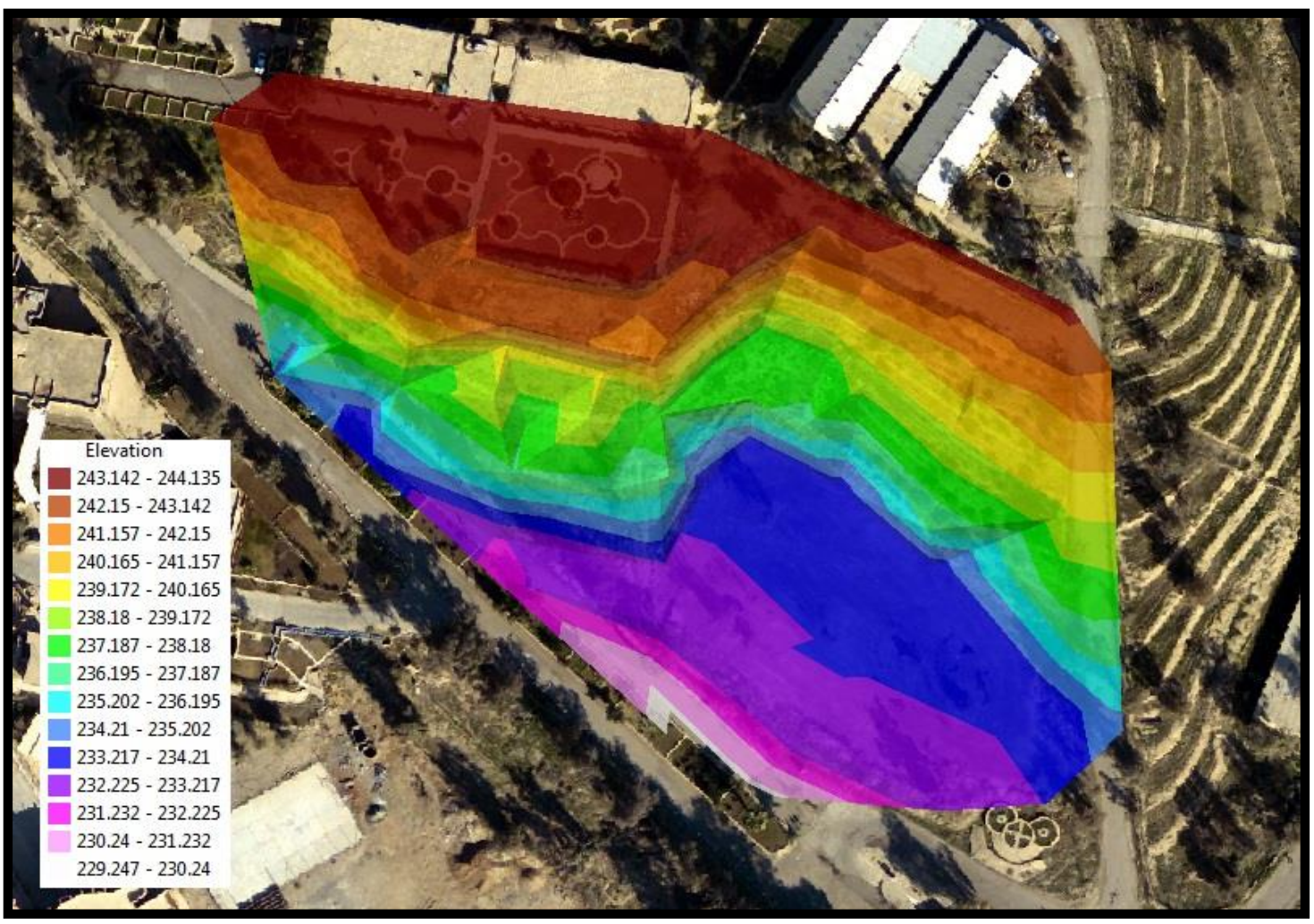

Fig. 14. Combination of the 3D tin and digital aerial photograph with transparency.

Relief representation diagrams using AutoCAD Civil 3D Land Software were shown in Figures 15 and 16 respectively. Contour map with $1 \mathrm{~m}$ interval was derived from DTM as shown in Figure 15. 3D relief representation was shown in Figure 16. with the area elevation in color and there percentage of each range. 


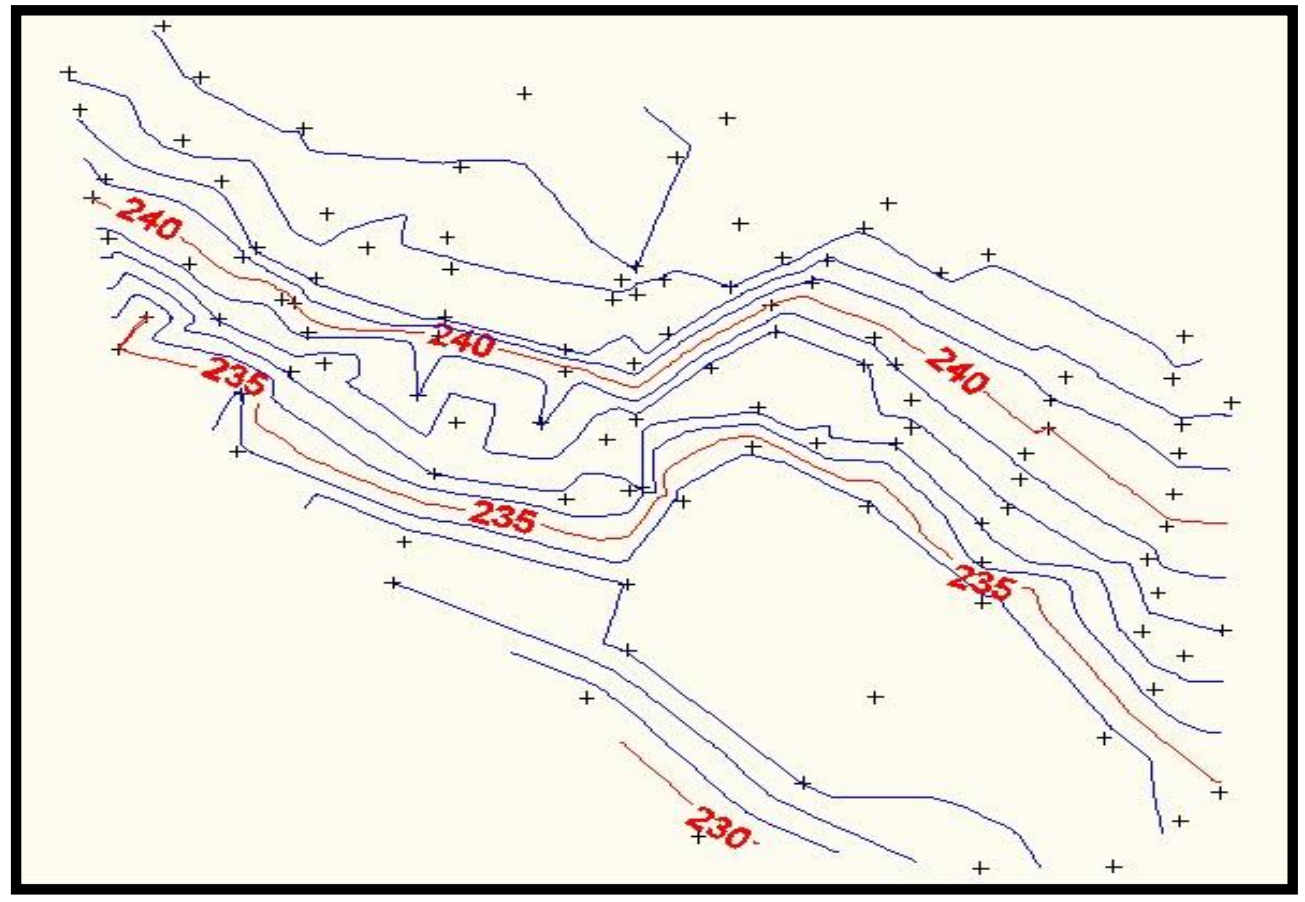

Fig. 15. Contour map with $1 \mathrm{~m}$ interval.

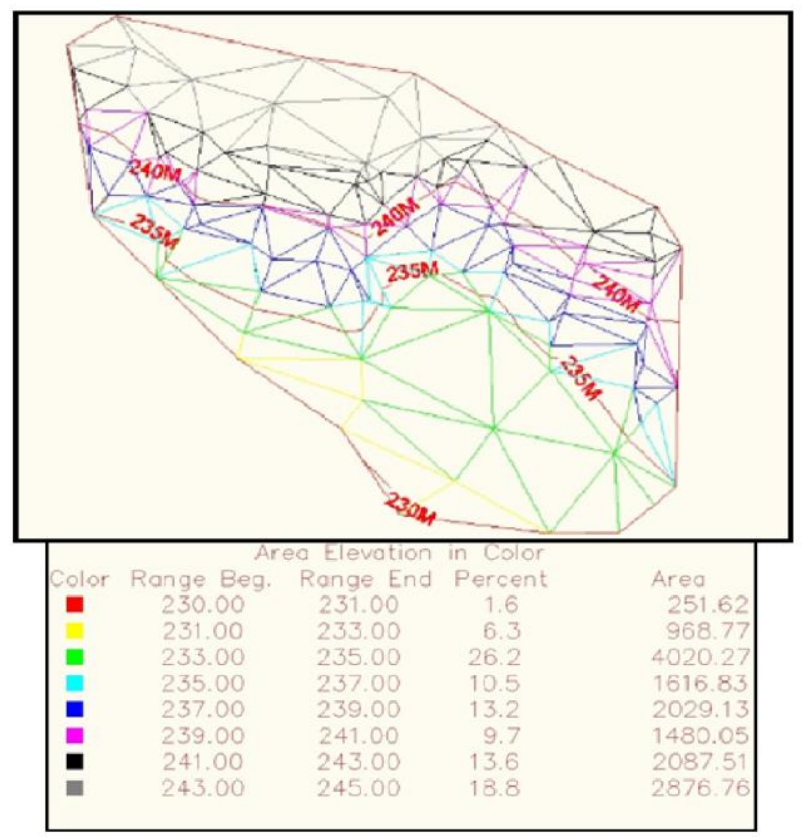

Fig 16. 3D relief representation with the area elevation in color. 


\section{Conclusions}

This research has demonstrated the use of the digital terrain model (DTM) for relief representation using different software's programming. Three computer software's were utilized for $2 \mathrm{D}$ and 3D relief representation namely ( GIS, Surfer and AutoCAD Civil 3D Land). Accordingly the results of the research we recommended use GIS for relief representation since it gives a wide range and different types of representation as well as suitable matching with terrain topography surface.

\section{References}

[1] Konecny G.: Geoinformation Remote sensing, photogrammetry and geographic information system. Taylor \& Francis, London and New York (2003).

[2] Karsli F., Ayhan E. and Tunc E.: Building 3D Photo-texture Model Integrated with GIS for architecture Heritage Conservation. KTU, Engineering USA (2009).

[3] Thanoon A.M.H and Ahmed K.A.: Hydrological Information Extraction for Dams site Selection Using remote sensing techniques and geographical information system. Vol. 21, No.5., pp. 102-114. ALRafidain Engineering Journal, Mosul Iraq (2013).

[4] ESRI, Manual of GIS 13, USA (2013).

[5] Surfer Access System, Version 13, Program package, copyright Golden Software, Inc, 13 (2013).

[6] AutoCAD Civil 3D 2013. 